\title{
HUBUNGAN DUKUNGAN KELUARGA DENGAN KEMANDIRIAN LANSIA DALAM MELAKSANAKAN PERSONAL HYGIENE DI KABUPATEN GIANYAR
}

\section{THE CORRELATION BETWEEN FAMILY SUPPORT WITH INDEPENDENCE OF THE ELDERLY IN IMPLEMENTING PERSONAL HYGIENE IN GIANYAR REGENCY}

\author{
I Komang Yoki Kirawan ${ }^{1}$, Diah Prihatiningsih ${ }^{2}$ \\ 1,2Program Studi Ilmu Keperawatan \\ Sekolah Tinggi Ilmu Kesehatan Wira Medika Bali
}

\begin{abstract}
ABSTRAK
Personal Hygiene adalah kemampuan seseorang untuk merawat diri sendiri mulai dari tidur, menadi, memakai baju dan seterusnya sampai akhirnya tidur kembali. Dengan kata lain, semua kegiatan yang dilakukan seseorang untuk merawat diri sendiri. Untuk mencapai tujuan ini diperlukan adanya dukungan keluarga sebagai salah satu faktor interpersonal untuk tercapainya kemandirian lansia dalam melaksanakan personal hygiene. Penelitian ini bertujuan untuk mengetahui hubungan dukungan keluarga dengan kemandirian lansia dalam melaksanakan personal hygiene. Penelitian ini menggunakan cross sectional. Teknik sampling pada penelitian ini menggunakan total sampling dengan 45 sampel. Berdasarkan uji korelasi Rank spearman menunjukan bahwa koefisien korelasi (r) $=0,425$ dengan koefisien korelasi kuat dan positif dengan nilai $p$ value $=0,004(p<a)$ yang berarti ada hubungan dukungan keluarga dengan kemandirian lansia dalam melaksanakan personal hygiene di Gianyar Berdasarkan hasil temuan di atas diharapkan bisa memberikan masukan dan informasi bagi masyarakat khususnya untuk lebih meningkatkan personal hygiene pada lansia agar lebih baik.
\end{abstract}

Kata Kunci: Dukungan Keluarga, Personal Hygiene, Lansia

\begin{abstract}
Personal hygiene is the ability of a person to take care of himself starting from sleeping, bathing, dressing and so on until he goes to sleep again, or all activities of people who take care of themselves. To achieve this goal family support is needed as one of the interpersonal factors to achieve the independence of the elderly in implementing personal hygiene. This study aims to determine the relationship of family support with the independence of the elderly in carrying out personal hygiene This study used cross sectional. The sampling technique in this study used all sampling with 45 samples. The results of the Rank Spearman correlation test showed that the correlation coefficient $(r)=0.425$ with a strong and positive correlation coefficient with a $p$ value $=0.004(p<a)$ which means there is a
\end{abstract}


Bali Medika Jurnal.

Vol 7 No 1, 2020: 77-85

ISSN : 2615-7047

DOI: https://doi.org/10.36376/bmj.v7i1

relationship between family support and elderly independence in implementing personal hygiene in Gianyar Based on the findings above can provide input and information for the community especially to further improve personal hygiene in the elderly to be better.

Key words: Family Support, Personal Hygiene, Elderly

\begin{tabular}{ll}
\hline Alamat Korespondensi & $:$ Jl. Kecak No.9A, Tonja, Kec. Denpasar Utara, Kota Denpasar, Bali 80239 \\
Email & :diahciprik@gmail.com
\end{tabular}

\section{PENDAHULUAN}

Peningkatan jumlah penduduk lansia (lanjut usia) pada dasarnya merupakan dampak positif dari derajat kesehatan masyarakat. Peningkatan kesejahteraan baik fisik maupun psikis akan meningkatkan usia harapan hidup lansia. Peningkatan usia harapan hidup mengindikasikan jumlah penduduk lanjut usia (lansia) dari tahun ke tahun semakin meningkat sehingga membawa pengaruh besar dalam pengelolaan masalah kesehatannya (Koswara, 2015).

Jumlah lansia di dunia menurut WHO (2015) pada tahun 2013-2020, akan menduduki peringkat teratas dibandingkan dari golongan usia dibawahnya yaitu $13,4 \%$ pada tahun 2015 dan $25,3 \%$ pada tahun 2016. Pertambahan penduduk lansia di Indonesia menunjukan adanya kecenderungan peningkatan jumlah lansia, pada tahun 2016 pertambahan lansia sebanyak 21,4\% (Kemenkes RI, 2016). Penduduk lansia terbanyak di Indonesia yaitu provinsi Daerah Istimewa Yogyakarta 13,04\%, sedangkan di posisi ke dua yaitu Jawa Timur 10,4\%, Jawa Tengah 10,34\% dan Bali berada di posisi ke empat yaitu sebanyak 9,78\% (BPS, 2016).

Jumlah penduduk lanjut usia di Provinsi Bali tahun 2016 sebanyak 462,822 jiwa. Jumlah penduduk lanjut usia tertinggi pertama berada di Kabupaten Gianyar sebesar 86.061 jiwa, dilanjutkan oleh Kabupaten Badung dengan jumlah lansia sebesar 78.170 jiwa, dan Kabupaten Tabanan sebesar 73.778 jiwa, Kabupaten Buleleng sebesar 64.620 jiwa, Kabupaten Karangasem sebesar 46.807 jiwa, Kabupaten Jembrana sebesar 35.598 jiwa, Kabupaten Klungkung sebesar 32.197 jiwa dan Kabupaten Bangli sebesar 22.777 jiwa, serta Kota Madya Denpasar sebesar 14.845 jiwa (Dinas Kesehatan Provinsi Bali, 2017).

Lansia merupakan kelompok berisiko (population at risk) dan kelompok rentan (vulnerable population). Permasalahan yang timbul pada lansia disebabkan oleh perubahan fisiologis secara bertahap. Masalah kesehatan yang sering terjadi pada lansia menurut Siburian (2015) sering disebut dengan istilah 14 I, yaitu immobility (kurang bergerak), instability (berdiri dan berjalan tidak stabil atau mudah jatuh), incontinence (beser buang air kecil dan atau buang air besar), intellectual impairment (gangguan intelektual/dementia), infection (infeksi), impairment of vision and hearing, taste, smell, communication, convalescence, skin integrity (gangguan panca indera, komunikasi, penyembuhan dan kulit), impaction (sulit buang air besar), isolation (depresi), inanition (kurang gizi), impecunity (tidak punya uang), iatrogenesis (menderita penyakit akibat obat-obatan), Insomnia (gangguan tidur), immune deficiency (daya tahan tubuh yang menurun), impotence (impotensi). 
Masalah kelemahan fisik pada lansia sangatlah berpengaruh pada perawatan diri. Apabila Seseorang tidak bias melakukan aktifitasnya tentunya kurang adanya perawatan diri yang baik pada lansia atau personal hygiene yaitu kemampuan seseorang untuk mengurus dirinya sendiri dimulai dari bagian tidur, mandi, berpakaian dan seterusnya sampai pergi tidur kembali, atau segala kegiatan orang yang mengurus dirinya sendiri (Fitria, 2009).

Dukungan keluarga adalah sikap, tindakan penerimaan keluarga terhadap anggota keluarganya, berupa dukungan informasional, dukungan penilaian, dukungan instrumental dan dukungan emosional. Jadi dukungan keluarga adalah suatu bentuk hubungan interpersonal yang meliputi sikap, tindakan dan penerimaan terhadap anggota keluarga, sehingga anggota keluarga merasa ada yang memperhatikannya (Fridman, 2014). Salah satu fungsi keluarga adalah fungsi asih dimana antara anggota keluarga saling memberikan kasih sayang dan rasa aman, memberikan perhatian dan kehangatan terutama pada lansia yang mengalami penurunan kemampuan fisik. Dalam teori kepribadian menurut Ericson menyatakan lansia yang usianya diatas 60 tahun merasa hidup mereka sudah dekat dengan akhir hayat dan pada masa ini kasih sayang dari lingkub keluarga terdekat merupakan kenikmatan tersendiri. Hal ini menunjukan bahwa keluarga sangat berpengaruh pada lansia baik secara fisik maupun psikologis.

Pemeliharaan kebersihan diri sangat menentukan status kesehatan, dimana individu secara sadar dan atas inisiatif pribadi menjaga kesehatan dan mencegah terjadinya penyakit. Upaya ini lebih menguntungkan bagi individu karena lebih hemat biaya, tenaga, dan waktu dalam mewujudkan kesejahtraan dan kesehatan. Solusi yang bisa dilakukan agar lansia mampu menjaga kebersihan diri salah satunya dengan memberikan motivasi pada lansia agar lansia yang kurang memiliki kemauan dalam melakukan kebersihan diri menjadi berkenan melakukan kebersihan diri dengan cara mengajak lansia untuk aktif dalam merawat dirinya yang meliputi kebersihan badan seperti mandi, mencuci rambut, dan menggosok gigi bagi lansia (Wartonah, 2010).

Berdasarkan data Gianyar (2018) jumlah penduduk lansia di Kabupaten Gianyar sebanyak 86.061 lansia dimana untuk Kabupaten Gianyar jumlah lansia terbanyak ada di wilayah Gianyar 1 dengan jumlah lansia 9.131. Berdasarkan studi pendahuluan yang dilakukan pada tanggal 1 Pebruari 2019 di Puskesmas 1 Gianyar didapat data, jumlah lansia di wilayah kerja Puskesmas 1 Gianyar yang mewilayah 10 desa. Menurut data di Puskesmas terdapat tiga desa dengan jumlah lansia terbanyak yaitu Desa Serongan dengan 708 lansia, Desa Sidan 674 lansia, Desa Samplangan 587 lansia. Menurut data dari tiga desa dengan jumlah lansia terbanyak yang berada di wilayah kerja Puskesmas 1 Gianyar, bahwa gangguan lansia dengan personal hygiene yang tertinggi di Desa Samplangan Lingkungan Bukit Batu sebanyak 45 orang.

Berdasarkan data diatas dan hasil wawancara terhadap petugas pemegang program lansia mengatakan jarang mendapatkan dukungan keluarga pada lansia yang melakukan personal hygiene, maka dari itu penulis sangat tertarik untuk melakukan penelitian tentang "Hubungan Dukungan Keluarga dengan Kemandirian Lansia Dalam Melakukan Personal Hygiene di Desa Samplangan Lingkungan Bukit Batu Gianyar". Alasan peneliti melakukan penelitian di Desa Samplangan adalah untuk mengetahui apakah ada hubungan antara dukungan keluarga dengan kemandirian lansia dalam melakukan personal hygiene yang 
Bali Medika Jurnal.

Vol 7 No 1, 2020: 77-85

ISSN : 2615-7047

DOI: https://doi.org/10.36376/bmj.v7i1

dimana Desa Samplangan merupakan salah satu desa dengan jumlah lansia tertinggi di Puskesmas 1 Gianyar.

\section{METODE PENELITIAN}

Penelitian ini menggunakan jenis penelitian kuantitatif dengan menggunakan desain cross secional. Penelitian ini merupakan penelitian observational (noneksperimental) dengan rancangan korelasional yaitu penelitian yang dilakukan untuk mengamati suatu gejala yang sedang terjadi tanpa melakukan tindakan. Penelitian ini telah dilakukan di wilayah kerja Puskesmas 1 Gianyar, Lingkungan Bukit batu Desa Samplangan, Gianyar. Penelitian ini telah dilakukan dari tanggal 28 April sampai 28 Mei 2019. Populasi dalam penelitian ini adalah Lansia yang mengalami personal hygiene di Lingkungan Bukit Batu Desa Samplangan sebanyak 45 lansia. Teknik sampling yang digunakan yaitu total sampling dengan sampel sebanyak 45 lansia. Instrumen pengumpulan data dalam penelitian ini dilakukan dengan menggunakan Kuesioner dukungan keluarga dan kuisioner personal hygiene. Analisa data yang digunakan adalah Uji rank spearman.

\section{HASIL DAN PEMBAHASAN}

Hasil Pengamatan Terhadap Objek Penelitian Berdasarkan Variabel Penelitian, Variabel yang diukur pada penelitian ini adalah Dukungan keluarga terhadap personal hygine pada lansia di Lingkungan Bukit Batu Desa Samplangan Gianyar.

Tabel 1.

Distribusi Frekuensi hubungan dukungan keluarga dengan kemandirian lansia dalam melaksanakan personal hygine

\begin{tabular}{llll}
\hline No & Dukungan Keluarga & Frekuensi (F) & Persentase (\%) \\
\hline 1 & Kurang & 2 & 4.4 \\
2 & Cukup & 20 & 44.4 \\
3 & Baik & 23 & 51.1 \\
\hline Jumlah & 45 & 100.0 \\
\hline
\end{tabular}

Berdasarkan tabel 1 hasil penelitian yang didapatkan bahwa sebagian besar Dukungan Keluarga yang baik 23 orang $(51,1 \%)$, yang cukup sebanyak 20 orang $(44,4 \%)$ sedangkan Dukungan Keluarga yang kurang sebanyak 2 orang $(4,4 \%)$.

Tabel 2.

Distribusi Frekuensi kemandirian lansia dalam melaksanakan personal hygine

\begin{tabular}{llll}
\hline No & Personal hygiene & Frekuensi $(\mathrm{F})$ & Persentase $(\%)$ \\
\hline 1 & Kurang & 1 & 2.2 \\
2 & Cukup & 21 & 46.7 \\
3 & Baik & 23 & 51.1 \\
\hline
\end{tabular}




\begin{tabular}{lll}
\hline Jumlah & 45 & 100.0 \\
\hline
\end{tabular}

Berdasarkan tabel 2 hasil penelitian yang didapatkan bahwa sebagian besar Personal Hygiene lansia yang baik sebanyak 23 orang $(51,1 \%)$, yang cukup sebanyak 21 orang $(46,7 \%)$ sedangkan Personal Hygiene Lansia yang kurang sebanyak 1 orang $(2,2 \%)$.

Tabel 3

Hasil Analisa Data Hubungan Dukungan Keluarga Dengan Kemandirian Lansia

Dalam

Melaksanakan Personal Hygiene Di Lingkungan Bukit Batau Desa Samplangan, Gianyar

\begin{tabular}{|c|c|c|c|c|c|c|c|c|c|}
\hline \multirow[t]{3}{*}{$\begin{array}{l}\text { Dukungan } \\
\text { Keluarga }\end{array}$} & \multicolumn{2}{|c|}{$\begin{array}{l}\text { Kemandirian } \\
\text { hygine lansia }\end{array}$} & \multicolumn{2}{|c|}{ personal } & Total & \multicolumn{2}{|r|}{$\mathbf{R}$} & \multirow{2}{*}{\multicolumn{2}{|c|}{$\mathbf{P}$}} \\
\hline & Kurang & $\mathbf{C u}$ & xup & $\mathrm{Ba}$ & & & & & \\
\hline & $\mathrm{F} \%$ & $\mathrm{~F}$ & $\%$ & $\mathrm{~F}$ & $\%$ & & & & \\
\hline Kurang & $1 \quad 50.0 \%$ & 1 & $50.0 \%$ & 0 & $0.0 \%$ & 2 & $4.4 \%$ & 0,425 & 0,004 \\
\hline Cukup & $0 \quad 0.0 \%$ & 13 & $65.0 \%$ & 7 & $35.0 \%$ & 20 & $44.4 \%$ & & \\
\hline Baik & $0 \quad 0.0 \%$ & 7 & $30.4 \%$ & 16 & $69.6 \%$ & 23 & $51.1 \%$ & & \\
\hline Total & $12.2 \%$ & 21 & $46.7 \%$ & 23 & $51.1 \%$ & 45 & $100.0 \%$ & & \\
\hline
\end{tabular}

Berdasarkan hasil pada tabel 4.12 didapat nilai korelasi sebesar 0,425 dan $p$ value $=0,004$. Dari hasil analisis dapat diketahui bahwa $p$ value $=0,004<\alpha=0,05$ yang artinya hipotesa dalam penelitian ini diterima dimana secara statistic ada hubungan positif dan signifikan dukungan keluarga dengan kemandirian lansia dalam melakukan personal hygine. Dilihat dari kuat lemahnya hubungan yang didapat dari hasil pengolahan data, maka nilai 0,425 berarti ada hubungan yang sangat kuat antara dukungan keluarga dengan kemandirian lansia dalam melaksanakan personal hygine.

\section{Mengidentifikasi Dukungan Keluarga Terhadap Lansia dalam melakukan personal hygine}

Berdasarkan hasil penelitian yang didapatkan oleh peneliti dari 45 responden (100\%) sebagian besar responden di Desa Samplangan Lingkungan Bukit Batu mendapatkan Dukungan Keluarga dengan katagori baik sebanyak 23 responden $(51,1 \%)$.

Menurut teori Friediman, 2010 Dukungan keluarga adalah sikap, tindakan penerimaan keluarga terhadap anggota keluargannya, berupa dukungan informasional, dukungan penilaian, dukungan instrumental dan dukungan emosional. Jadi dukungan keluarga adalah suatu bentuk hubungan interpersonal yang meliputi sikap, tindakan dan penerimaan terhadap anggota keluarga, sehingga anggota keluarga merasa ada yang memperhatikannya. Tujuan dukungan keluarga sangatlah luas diterima bahwa orang yang berada dalam lingkungan keluarga yang suportif umumnya memiliki kondisi yang lebih baik dibandingkan rekannya yang tanpa keuntungan ini. Lebih khususnya, karena dukungan sosial keluarga dapatdianggap mengurangi beban dan dapat meningkatkan kesehatan mental 
individu atau keluarga secara langsung, dukungan sosial adalah strategi penting yang harus ada dalam masa stress bagi keluarga dan sebagai pencegahan strees.

Sistem dukungan keluarga ini dapat membantu tugas yang sering kali diberikan oleh keluarga besar, teman, dan tetangga. Bantuan dari keluarga besar juga dilakukan dalam bentuk bantuan langsung, termasuk bantuan terus-menerus, berbelanja, merawat anak, perawatan fisik lansia, melakukan tugas rumah tangga, dan bantuan praktis selama masa krisis (Sunaryo, 2014).

Penelitian ini sejalan dengan penelitan yang dilakukan oleh Septia, (2013) dengan judul Hubungan Dukungan Keluarga Dengan Kepatuhan Minum Obat Pada Penderita Tb Paru. Hasil yang didapat terdapat dukungan keluarga dengan katergori baik yaitu $75 \%$ dari 20 responden. Persamaan penelitian yang dilakukan oleh Septia dengan yang dilakukan oleh peneliti yaitu sama sama mendapatkan hasil dukungan keluarga dengan kategori baik.

Peneliti berpendapat faktor yang mempengaruhi dukungan keluarga yaitu factor internal dan eksternal. Kedua faktor ini sangat penting dalam kelangsungan hidup lansia terutama masalah personal hygine lansia. Dari dukungan keluarga inilah lansia bisa dibina dalam menjaga kebersihan dini atau personal hygine. Dalam penelitian yang dilakuan oleh peneliti di desa samplangan lingkungan bukit batu sebagian besar keluarga sudah mampu memberi dukungan atau membina lansia dalam menjaga kebersihan diri atau personal hygine. Jadi dapat disimpulkan bahwa sebagian besar dukungan keluarga yang didapat oleh lansia dalam melaksanakan personal hygine dapat dikategorikan baik.

\section{Mengidentifikasi kemandirian lansia dalam melakukan personal hygiene}

Berdasarkan hasil penelitian yang didapatkan oleh peneliti dari 45 responden (100\%) sebagian besar responden di Desa Samplangan Lingkungan Bukit Batu mendapatkan kemandirian dalam melakukan personal hygine dengan katagori baik sebanyak 23 responden $(51,1 \%)$.

Personal hygiene adalah kemampuan seseorang untuk mengurus dirinya sendiri dimulai dari bagian tidur, mandi, berpakaian dan seterusnya sampai pergi tidur kembali, atau segala kegiatan orang yang mengurus dirinya sendiri (Fitria, 2009). mengungkapkan bahwa ada beberapa point penting dalam melakukan personal hygiene yakni :(mandi, berpakaian, toileting, makan), berpindah/pergerakkan, pekerjaan rumah tangga, kemampuan untuk menangani keuangan, tanggung jawab untuk pengobatan sendiri, transportasi dan laundry (Surya, 2011).

Keterbatasan perawatan diri diatas biasanya diakibatkan karena stressor yang cukup berat dan sulit ditangani oleh pasien, sehingga dirinya tidak mau mengurus atau merawat dirinya sendiri baik dalam hal mandi, berpakaian, berhias, makan, maupun BAB dan BAK. Bila tidak dilakukan intervensi oleh petugas kesehatan maka maka kebutuhan dasar lainnya dapat terganggu (Fitria, 2009).

Penelitian ini sejalan dengan penelitan yang dilakukan oleh Sutrisnayanti (2016) yang berjudul Hubungan Tingkat Pengetahuan Tentang Personal Hygiene Dengan Prilaku Lansia Dalam Pemenuhan Personal Hygiene. Hasil penelitian sebagian besar responden memiliki pengetahuan yang baik tentang Personal Hygiene yaitu sebanyak 100 dan katagori prilaku sebagian besar responden dalam katagori baik yaitu sebanyak $82 \%$. Persamaan dengan penelitian yang dilakukan oleh Dewi Sutrisnayanti dengan yang dilakukan oleh peneliti yaitu sama sama 
medapatkan hasil kemandirian lansia dalam melaksanakan personal hygine dengan kategori baik.

Peneliti berpendapat bahwa salah satu masalah yang sering dialami oleh lansia yaitu gangguan personal hygine. Di desa samplangan lingkungan bukit batu sebagian besar lansia tidak ada masalah dengan gangguan personal hygine dapat dikategorikan baik. Dari 45 responden 23 diantaranya memiliki kemandrian dalam melaksanakan personal hygine dengan baik. Salah satu factor yang mempengaruhi personal hygine yaitu pekerjaan. Pada penelitian ini sebagian besar lansia bekerja sebagai wiraswasta jadi lansia di desa samplangan lingkungan bukit batu bisa menyempatkan diri untuk menjaga kebersihan diri atau personal hygine. Jadi dapat disimpulkan bahwa kemandirian lansia dalam melaksanakan personal hygine di Desa samplangan Lingkungan Bukit Batu dapat di kategorikan dengan baik.

\section{Menganalisis hubungan dukungan keluarga dengan kemandirian lansia dalam melaksanakan personal hygiene}

Berdasarkan hasil analisa dari hasil penelitian di dapatkan hasil dukungan keluarga yang kurang dengan kemandirian personal hygine yang kurang $(50,0 \%)$ memiliki dukungan keluarga yang kurang dengan kemandirian personal hygine yang cukup, $(65,0 \%)$ memiliki dukungan keluarga yang cukup dengan kemandirian personal hygine yang cukup, $(35,0 \%)$ memiliki dukungan keluarga yang cukup dengan kemandirian personal hygine yang baik, (30,4\%) memiliki dukungan keluarga yang baik dengan kemandirian personal hygine yang cukup dan $(69,6 \%)$ memiliki dukungan keluarga yang baik dengan personal hygine yang baik. didapat nilai korelasi sebesar 0,425 dan $p$ value $=0,004$. Dari hasil analisis kemandirian personal dapat diketahui bahwa $p$ value $=0,004<\alpha=0,05$ yang artinya hipotesa dalam penelitian ini diterima dimana secara statistic ada hubungan positif dan signifikan dukungan keluarga dengan kemandirian lansia dalam melakukan personal hygine. Dilihat dari kuat lemahnya hubungan yang didapat dari hasil pengolahan data, maka nilai 0,425 berarti ada hubungan yang sangat kuat antara dukungan keluarga dengan kemandirian lansia dalam melaksanakan personal hygine.

Hubungan Dukungan Keluarga Dengan Kemandirian Lansia Dalam Melaksankan Personal Hygiene yaitu dukungan dan keterlibatan keluarga serta perhatian keluarga terhadap kualitas hidup agar makin lebih baik. Kebutuhan hidup lansia lainnya dapat terpenuhi dengan baik melalui dukungan informasional seperti pemberian informasi, dukungan instrumental seperti bantuan materi, dukungan emosional seperti rasa kenyamanan dan dukungan penilaian seperti pemberian support

Dukungan keluarga adalah sebagai suatu proses hubungan atara keluarga dengan lingkungan sosial. Semua tahap, dukungan sosial keluarga menjadikan keluarga mampu berfungsi dengan berbagai kepandaian dan akal, sehingga akan meningkatkan kesehatan dan adaptasi mereka dalam kehidupan (Setiadi, 2007).

Lansia yang dukungan keluarganya tinggi maka pemenuhan kebutuhan Personal Hygiene juga cenderung tinggi. Adanya pengaruh dukungan keluarga dalam keikutsertaan yang dimiliki oeleh lansia maka mereka mampu melakukan Personal Hygiene meskipun terkadang perlu ada bantuan orang alin selain keluarga. Begitu pula sebaliknya, apanila lansia dukungan keluarga rendah maka mereka tidak akan memenuhi kebutuhan Peraonl Hygiene maka dapat berakibat pada 
dampak fisik maupun fisikologis. Hal tersebut konsisten dengan tiori yang dikemukakan oleh Hidayat (2007).

Menurut pendapat peneliti keberhasilan dalam kemandirian lansia melakukan personal hygine yaitu dukungan keluarga. Jika dukungan keluarga baik dalam membina personal hygine lansia akan mengakibatkan kemandirian lansia akan baik dan jika dukungan keluarga dalam merawat personal hygine lansia kurang maka kemandirian lansia dalam melaksanakan personal hygine akan kurang. Disinilah pentingnya dukungan keluarga dalam merawat lansia agar lanisa tetap mandiri dalam menjaga personal hygine. Jadi dapat disimpulkan bahwa ada hubungan yang kuat antara hubungan dukungan keluarga dengan kemandirian lansia dalam melakukan personal hygine.

\section{SIMPULAN DAN SARAN}

\section{Simpulan}

Berdasarkan hasil analisa dan pembahasan tentang hubungan dukungan keluarga terhadap lansia yang mengalami personal hygine di lingkungan Bukit batu desa samplangan Gianyar yang telah diuraikan sebelumnya dapat ditarik kesimpulan sebagai berikut: Dukungan keluarga, Lingkungan Bukit Batu Desa Samplangan Kabupaten Gianyar tahun 2019 dikatagorikan baik (51,1\%), Kemandirian lansia dalam melaksanakan Personal Hygiene, di Desa Samplangan Lingkungan Bukit Batu Kabupaten Gianyar Tahuan 2019 dikatagorikan baik (51,1\%). Ada hubungan antara Dukungan Keluarga dengan keemandirian lansia dalam melaksanakan personal hygiene di Desa Samplangan Lingkungan Bukit Batu Gianyar Tahun $2019(\mathrm{p}=0,004 \mathrm{r}=0,425)$, yang menunjukan bahwa dukungan keluarga baik maka kemandirian lansia dalam melakukan personal hygiene juga baik, dengan kekuatan korelasi yang sangat kuat. Jika dukungan keluarga baik dalam membina personal hygine lansia akan mengakibatkan kemandirian lansia akan baik dan jika dukungan keluarga dalam merawat personal hygine lansia kurang maka kemandirian lansia dalam melaksanakan personal hygine akan kurang.

\section{Saran}

Berdasarkan penelitian ini, Bagi keluarga disarankan Perlu ditingkatkan dalam hal pemberian informasi khususnya personal hygiene kepada lansia melalui penyuluhan agar pengetahuan lansia meningkatkan tentang personal hygiene. Bagi Masyarakat disarankan Hasil penelitian ini bisa memberikan masukan dan informasi bagi masyarakat khususnya untuk lebih meningkatkan personal hygiene pada lansia agar lebih baik. Bagi peneliti selanjutnya, diharapkan Hasil penelitian ini dapat memberikan masukan sehingga dapat digunakan untuk penelitian selanjutnya misalnya Dukungan Keluarga dengan tingkat kesembuhan penyakit

\section{DAFTAR PUSTAKA}

BPS. (2016). Badan Pusat Statistik RI. http://www.bps.go.id/

Dinas Kesehatan Provinsi Bali. (2017). Profil Kesehatan Provinsi Bali. Dinas 
Bali Medika Jurnal.

Vol 7 No 1, 2020: 77-85

ISSN : 2615-7047

DOI: https://doi.org/10.36376/bmj.v7i1

Kesehatan.

Fitria, N. (2009). Prinsip Dasar dan Aplikasi Penulisan Laporan Pendahuluan dan Strategi Pelaksanaan Tindakan Keperawatan (LP dan SP). Salemba Medika.

Fridman, L. M. (2014). Buku Ajaran Keperawatan Keluarga. EGC.

Gianyar, D. K. K. (2018). Profil Kesehatan Kabupaten Gianyar. Dinas Kesehatan.

Hidayat. (2007). Riset Keperawatan dan Teknik Penulisan Ilmiah. Salemba Medika.

Kemenkes RI. (2016). Buletin Gambaran Kesehatan Lanjut Usia di Indonesia. www.depkes.go.id/dowloads/Buletinlansiapdf

Koswara. (2015). Psikologi Usia. http://www.e-psikologi/usia/2.htm

Septia, A. S. (2013). Hubungan dukungan keluarga dengan kepatuhan minum obat pada penderita tb paru. 1-10.

Setiadi. (2007). Konsep dan Penulisan Riset Keperawatan. Graha Ilmu.

Siburian. (2015). Bagaimana Memberdayakan Kemampuan Fisik Lansia. www.waspada.co.id/cetak/index.ph p?article_id=74423

Sunaryo. (2014). Psikologi Untuk Keperawatan. EGC.

Surya, D. (2011). Buku Ajar Asuhan Keperawatan Jiwa. Nuha Medika.

Wartonah, T. (2010). Kebutuhan Dasar manusia dan Proses Keberawatan. Salemba Medika.

WHO. (2015). WHO Global Report on Falls Prevention in Older Age. World Health Organitation. 